\title{
Characterization of Multicultural Values: Affective Impact of Writing Extensive Journals in a University-Level Course
}

\author{
Taekhil Jeong \\ School of Education, Indiana University Kokomo, Kokomo, USA \\ Email: jeongt@iuk.edu
}

Received May 21 ${ }^{\text {st }}, 2013$; revised June $22^{\text {nd }}, 2013$; accepted June $30^{\text {th }}, 2013$

Copyright (C 2013 Taekhil Jeong. This is an open access article distributed under the Creative Commons Attribution License, which permits unrestricted use, distribution, and reproduction in any medium, provided the original work is properly cited.

\begin{abstract}
The highest educational objective of affective domain is characterization, which refers to the level of character development where individuals' behaviors and values remain consistent. Because the educational objectives of affect are categorically different from cognitive educational objectives, an alternative pedagogical conceptualization that integrates teaching, learning, and evaluating aspects of character development is essential in multicultural education. The current action research presents: 1) a rubric of multicultural education journal writing that evaluates the quality of students' journals; 2) coherent journal topics and accessible resources for journal entries; and 3) exemplary student journals that sufficiently meet the criteria of rubric, topic, and resource requirements. The presented rubric, topics, resources, and actual student journal examples may serve as a model that both multicultural education teachers and students alike can utilize in their teaching and learning practices.
\end{abstract}

Keywords: Multicultural Education; Educational Objectives of Affective Domain; Journal Writing; Characterization; Rubric; Perspective-Taking

\section{Introduction}

Where an affective variable refers to systematic evidence regarding individuals' different degrees of emotions, interests, attitudes, and values (Krathwohl, Bloom, \& Masia, 1964), affect is a fundamental aspect of being human because it plays such an integral role in human motivation and behavior (Reeve, 2005). Nevertheless, most educators agree that adequate amounts of instructional time and educational efforts should be invested in enabling learners' growth in affective domains (Banks, 2014; Bennett, 2011; Ford, 2011). The results from numerous quantitative and qualitative studies support that attitude toward learning (Dompnier, Darnon, \& Butera, 2009; Elik, Wiener, \& Corkum, 2010; Shirbagi, 2010), interest in a particular subject (Kerger, Martin, \& Brunner, 2011; Sarwar, Yousuf, \& Ranjha, 2011), and (dis)respect for teachers (Poulou, 2009; Shadreck \& Isaac, 2012) play a major role in students' learning accomplishments. However, the affection-related educational goals have received inadequate attention in traditional educational settings (Krathwohl et al., 1964; Ford, 2011). Each student in a classroom is a holistic individual with affective and cognitive sensibility, and thus investments of instructional time and educational resources have to be balanced between the

\footnotetext{
*In keeping up with technologically experienced students of the digital generation, the campus in which the current study was conducted has actively utilized an intuitive and user-friendly online learning system named ONCOURSE. The system supplements the limitations of class instructional times with the management of student grades, assignments, announcements, messages, and instructional resources while functioning virtually all the time. All of the journal topics, resources, and rubric are posted and available on the ONCOURSE system.
}

growth of affective characters and the proliferation of content knowledge. For this reason, educators have been concerned with the question of "not just what to teach but how to teach" (cited in Cook, 2000: p. 13). Moreover, with advancement of assessment theory and practice, educators are now encouraged to align students' formal learning experiences not only over curricular and instructional domains but over assessment and evaluation domains as well (McMillan, 2007; Popham, 2011). The current paper purports to explore such a pedagogical approach that includes assessment, learning, and teaching which are integrated within a university-level multicultural education course entitled Teaching in Pluralistic Society.

Banks (2014) conceptualizes that the constituents of effective multicultural education should include intellectual sophistication, emotional empowerment, and a concrete action plan for learners. Pre-service teachers' intellects can be sophisticated by learning about cultural pluralism and various ethnicities represented in our nation's diverse classrooms. Teachers' cognitive sophistication ramifies their pedagogical skills and strategies into authentic assessment, understanding of students' different learning styles, and culturally responsive teaching strategies. In a similar vein, having a concrete plan of action with multicultural awareness results in constructing culturally competent lesson plans in one's own subject areas and grade levels. Those two components of multicultural education typically involve cognitive process, and produce concrete outcomes such as test scores and constructed lesson plans. However, emotional empowerment involved with educational objectives of the affective taxonomy tends to produce less tangible outcomes such as value development or character growth, where taxonomy refers 
to the science of description, identification, naming, and classification (Krathwohl et al., 1964).

The component of emotional empowerment is of particular interest to the current action research. Action research is defined as, "research in which the practitioner is engaged in collecting data or information for the purpose of solving a practical problem in an authentic setting” (Nolen \& Vander Putten, 2007: p. 406). Because affective educational objectives are very different from those of cognitive educational objectives (Krathwohl et al., 1964), there have been attempts to re-conceptualize the process of instruction and assessment as an interactive dynamic of affective development for pre-service teachers (Ford, 2011; Popham, 2011). Those innovative approaches of instruction and assessment should contribute to the efficacy of multicultural education by providing direct hints to guide pre-service teachers' learning and by evaluating their educational progress. Such instruction and assessment should permit not only summative but also formative feedback as an integral part of the teaching and learning process. Moreover, it would be ideal if such a learning approach allows students with the opportunities of self-regulation and autonomous choices. In order to actualize such pedagogical visions, I have required students to write extensive journals as a course requirement in my multicultural education course. Journal writing refers to the activities of reflections and consequent writings, where "the very production and acquisition of knowledge" is being constructed and contested by students' writing activities (Giroux, 1991: p. 512). Epistemologically, journal writing is a constructivist approach as Banks (2014) conceptualizes, "when teachers engage students in knowledge construction, the students are given opportunities to participate in building knowledge and to construct their own interpretations of historical, social, and current events” (p. 88).

\section{Review of Literature}

The purpose of current action research is to develop a model that effectively puts a journal writing assignment as a course requirement into pedagogically sound practice in a universitylevel multicultural education course. Action research typically involves cyclic problem-solving activities, in which a researcher takes an initial action to resolve the identified problem and involves interactive reflections about the efficacy of the engaged action (Check \& Schutt, 2012). Fraenkel and Wallen (2009) indicated that action research is fundamentally different from all the other traditional research methodologies. Action research focuses "on getting information that will enable them (researchers) to change conditions in a particular situation in which they are personally involved" (Fraenkel \& Wallen, 2009: p. 13). I conceptualize that action research is not only methodologically different from traditional hypothesis-testing studies as Fraenkel and Wallen (2009) proposed, but also requires a different format of research report, which typically entails useful model, product, information, and practical propositions. The research question I focus on in the current study is, "What constitutes effective practices of the journal writing assignment as a college-level course requirement?", and "What does the product of each component of effective journal writing practice in the multicultural education course look like?" For the first research question, I would like to construct a clear rubric that guides and evaluates the quality of journal writing, and compile coherent topics and resources of journal writing entries. For the second research question, I would like to present the constructed rubric, the suggested topics and resources, and actual student products of exemplary journals. Therefore, the current action research purports to construct pedagogical products that will facilitate the growth of students' multicultural values through journal writing practices.

Krathwohl et al. (1964) published taxonomy of affective educational objectives as an extension of hugely successful Taxonomy of Educational Objectives, Handbook I: The Cognitive Domain (Bloom, 1956). Krathwohl et al. (1964) conceptualized that higher order affective characteristics such as valuing, organization, and characterization requires "far more effort and far more complex sets of arrangements than are usually provided in particular classroom lessons and sessions" (p. 78). Valuing refers to the development of a sense of responsibility and commitment to a particular value, organization refers to the establishment of a conscientious base for making decisions, and characterization refers to the demonstration of behaviors consistent with one's value system. Those prerogatives of "far more complex sets of learning arrangements" of Krathwohl et al. (1964) have been pursued as journal writing assignments in my multicultural education course. Christine Bennett (2011) conceptualized, "multicultural education has ideological overtones based on democratic ideals” (p. 10), and multicultural education encompasses four core values: 1) acceptance and appreciation of cultural diversity; 2) respect for human dignity and universal human rights; 3) responsibility to the world community; and 4) respect for the earth. The four multicultural core values can be equated with the higher-order affective educational objectives such as valuing, organization, and characterization. With the afore-going conceptualization, therefore, the relationship of educational objectives between multicultural education and affective education is compatible and transposable.

Banks (2009) conceptualized four levels of approaching multicultural education curricular content: 1) contributional, 2) additive, 3) transformative, and 4) social action. The contributional approach refers to a focus on ethnic heroes, holidays, and discrete cultural elements. The additive approach refers to the integration of multicultural concepts, contents, themes, and perspectives into curricular contents without changing the curriculum structure. The transformative approach refers to significant changes of curricular contents that enable students to view concepts, issues, events, and themes from the multiple perspectives of diverse ethnic and cultural groups. The social action approach refers to the level in which students make decisions on important social issues and take actions to help solve the social problems.

Synthesizing the conceptualizations of hierarchical affective educational objectives (Krathwohl et al., 1964) and multicultural curricular content structures (Banks, 2009), the following flow chart-like rubric was constructed to measure the quality of students' multicultural education journals. A good rubric should allow instructors to identify the skills that students have acquired and skills that remain unchallenged. Such information is necessary if teaching is to be responsive to students' needs. From the learners' vantage point, rubric criteria should be a natural fit for the assignment (i.e., the assignment must be designed to address each specific criterion). In addition, the instructor should consistently value and support the rubric criteria by providing much formative evaluation feedback that adequately and appropriately guides students' growths of multi- 
cultural values.

\section{Research Method}

The prerequisite of extensive journal writings as a multicultural education course requirement should include: 1) developing and constructing a rubric that guides the affective growth of students, evaluating the quality of students' journals; 2) sharing and suggesting coherent topics and readily available resources for journal entries, and 3) introducing exemplary students' journal writings that adequately meet the above requirements of rubric, topic, and resource. The rubric, topics, resources, and actual journal examples may serve as a model that both multicultural education teachers and students alike can utilize in their teaching and learning practices.

\section{Participants and Procedure}

The participants of the current study include 15 students who gave written voluntary permission on the Consent Form, out of the total 17 enrolled students in the M300 course, entitled Teaching in Pluralistic Society during the spring semester of 2013. In this course, each student is required to submit the same set of journal writings twice, one as an off-line paper copy and the other as an on-line ONCOURSE* electronic attachment. The conventional paper copy journal submissions are graded and returned to each student with the instructor's feedback and grade within the two weeks from the submission date. While the researcher is away from the classroom during the consent procedure, another faculty member of the School of Education would visit the class with the voluntary consent forms to conduct the students' consent process and explain that the collected consent forms will be sealed and kept in a separate envelope in a secure vault in her office. The researcher (the instructor of record) is unable to access the consent forms until the semester is completely over, thus guaranteeing that each student's journal grades (or any other grades for that matter) would not be affected by his or her consent or non-consent status. After the semester grade has been posted and the semester officially concluded, the researcher is provided with the collected consent forms. At this point, the researcher meticulously expunges out any identifiers that may possibly lead to the identity of a student from the electronic sets of multicultural education journals from only those students who gave consent. Moreover, the selected journal entries are strictly referred to as example 1, example 2, and so forth. With those aforementioned consent procedures and the participant anonymity protections, students' identities will not be revealed while the study is being conducted or when the study is reported or published.

\section{Research Design}

The current study will benefit in determining the pedagogical soundness of extensive journal writings as a major course requirement in a multicultural education course. In addition, if the current study report is published, it may provide other multicultural education students and teachers alike with information regarding a journal evaluation rubric, journal topics, and related resources. Where action research is defined as "research conducted by one or more individuals or groups for the purpose of solving a problem or obtaining information in order to inform local practice (Fraenkel \& Wallen, 2009: p. 589), the current study utilizes the research design of qualitative practice-oriented action research. The current study is qualitative in its research design: collecting and analyzing narrative data (i.e., students' exemplary journal entries) without assigning numeric value system such as Likert-scales. The current study is practice-oriented in nature because the products of the current study promotes a model of the multicultural education rubric of journal writing, and the topics and the resources of refined journal entries that I consider useful and effective to facilitate the characterization of multicultural values for the students.

\section{Result and Discussion}

In the section that follows, the constructed rubric of multicultural education journal writing (Table 1), suggested journal entry topics and related resources, and actual exemplary students' journal entries are presented and discussed.

\section{Rubric of Multicultural Education Journal Writings}

The spirit of the overarching journal writing assignment can be summarized using the terms of authenticity, creativity, and reflection. Authenticity refers to being genuine with oneself (i.e., discuss what/how each student feels about the multicultural issue under consideration). For this aim, the first-person speech in the journal narratives is used and expected to discuss each student's own thought, morale, and lesson, not to discuss others' or textbook authors' ideas. Creativity refers to expanding the multicultural discourses beyond the boundary of course textbook discussions. Students are encouraged to add, substantiate, expand, and construct multicultural reflection narratives from the contexts of situated personal and community level to those paradigms of historical, societal, national, and global perspective. Reflectivity refers to the quality of journal writings to be more transformative and characterization-oriented. Persuasive narratives or expository action plans including lesson (unit) plans to present solutions to social and educational problems, ideas, and perspectives to impart multicultural values should be esteemed with more weight.

\section{Suggested Journal Entry Topics and Related Resources}

The purpose of the journal writing assignment is to heighten students' cultural sensitivity of important multicultural issues and to build a reflective learning platform for multicultural education over an entire semester of the course duration. Students should commit to one journal entry per week, each entry being typically one and a half pages in length, with a minimum of 15 entries totaling about 20 pages. Journal topics should derive from answering the suggested journal topics, reading the course texts, class discussions, field participations, and the experiences of students. Contemporary mass media news also can be an excellent source for students' journal reflections.

1) What is multicultural education? Is it necessary? Why? Why not? (Bennett, 2011: ch. 1).

2) What characteristics does a culturally competent teacher demonstrate in and out of the classroom? How do I prepare myself to be a culturally sensitive individual? (Bennett, 2011: ch. 3). 3) What are the four core values of multicultural education? If you are to choose only 3 out of the 4 ? Only 2? Only 1 ? Why? Please articulate the reasons as to your priority. (Bennett, 2011: ch. 2). 
Table 1.

Rubric of multicultural education journal writings.

\begin{tabular}{|c|c|c|}
\hline \multicolumn{3}{|c|}{ English Conventions \& Lengths } \\
\hline 5 points & 3 - 4 points & 0 - 2 points \\
\hline $\begin{array}{l}\text { - Each entry is well-written with no English } \\
\text { conventional errors } \\
\text { - All journal content fits well on one and a half } \\
\text { pages of A4 size paper }\end{array}$ & $\begin{array}{l}\text { - Each entry is written with no notable English } \\
\text { conventional errors } \\
\text { - All journal content fits well on one and a } \\
\text { quarter pages of A4 (12-pt. fonts; double- spaced) }\end{array}$ & $\begin{array}{l}\text { Each entry is written with a few English } \\
\text { conventional errors }(1-2) \\
\text { - All journal content fits less than sufficiently } \\
\text { on a typical A4 size paper }\end{array}$ \\
\hline$\downarrow$ & $\downarrow$ & $\downarrow$ \\
\hline
\end{tabular}

If the overall content is tangential to multicultural education, then add 1 - 2 points

The tangential nature of journal quality is defined as introducing ethnic heroes, holidays, and discrete cultural elements in a remote manner where the overall tones of journal reflections are relativistic, ethnocentric, and those perspectives of others.

If the overall content is additive to multicultural education, then add 2 - 3 points

The additive nature of journal quality is defined as adding multicultural content, concepts, themes, and perspectives into one's own journal writing without obvious evidence of reaching either transformative or characterized level of affective growths.

If the overall content is transformative to multicultural education, then add 3 - 4 points

The transformative nature of journal quality is defined such that students are able to see multicultural contents, concepts, themes, and perspectives from pluralistic views of diverse cultural and ethnic groups sympathetically in others' shoes.

If the overall content is focused on authentic growths of character or oriented to a concrete action plan pertaining to multicultural education, then add 4 - 5 points

The characterizational nature of journal quality is defined such that students are able to make either important decision about or to construct plans on multicultural content, concepts, themes, and perspectives into one's own behavioral action codes, instructional lesson (unit) plans, and persuasive arguments or narratives for social-problem-solving.

4) What are some conscious or unconscious stereotypes/ prejudices that I have? How do I adequately keep them in control? (Bennett, 2011: ch. 3).

5) Cultural assimilation versus cultural pluralism, which is more agreeable to you? Why? (Bennett, 2011: ch. 1).

6) How do I develop culturally competent lesson plans in my subject/grade area/level? Construct your own lesson (unit) plan, or choose a multicultural lesson (unit) plan, and articulate what elements of the lesson plan you liked most, disliked, or want to modify. Why? [Lesson plan examples are available from Banks (2014: pp. 96-111)].

7) What would be the limitations of having only one perspective on social issues? What would be some benefits of having multiple perspectives on a social issue? (Bennett, 2011: ch. 2).

8) What are some strategies to ensure "optimal learning” for all students? (Strategies Table available at ONCOURSE site), summarizing; Williams, R. B., \& Dunn, S. E. (2008). Brain Compatible Learning for the Block (2nd Ed.). Thousand Oaks, CA: Corwin Press.

9) Identify and create an example of "Taxonomy of Affective Educational Objectives” of Krathwohl et al. (1964) (Summary Table available at ONCOURSE site), summarizing; Krathwohl, D. R., Bloom, B. S., \& Masia, B. B. (1964). Taxonomy of Educational Objectives: Handbook II-Affective Domain. White Plains, NY: Longman Inc.

10) Reflection on poverty simulation activity-"Wealth matter"-available at http://www.tolerance.org/lesson/wealth-matters and the case of DeAnne (Ford, 2011: pp. 287-289).

11) Reflection on "Acting White" (Cook \& Ludwig, 2008: pp. 275-297) and the case of DeWayne (Ford, 2011: pp. 99-
101).

12) Reflection on identity theories (Bennett, 2011: pp. 87-91) and the case of Ramirez (Ford, 2011: pp. 239-240).

13) Reflection on "Scientific Racism"-Nobel Prize winner (1962) Dr. James Watson’s case available at

http://www.independent.co.uk/news/science/fury-at-dna-pionee rs-theory-africans-are-less-intelligent-than-westerners-394898.h tml

14) Articulate bibliotherapy plans from the provided list of sample multicultural literature (Ford, 2011: pp. 229-230).

15) Identify and apply "micro-aggression themes and message” by Sue et al. (2007, 2010) (Ford, 2011: p. 223).

16) Reflection on videos from "GLTB bullying in school" available at http://www.glsen.org/cgi-bin/iowa/all/library/record/ 2722.html

17) Reflection on "Understanding the Foundation of Ethical Reasoning” by Dr. Richard Paul and Dr. Linda Elder (PDF file available at https://www.google.com/\#hl=en\&sclient=psyab\& $\mathrm{q}=$ Understanding + the + Foundation + of + Ethical+Reasoning $\% \mathrm{E}$ $2 \% 80 \% 9 \mathrm{D}+$ by+Dr.++++++++++Richard+Paul+and+Dr.+Lind a+Elder $+\& o q=$ Understanding + the + Foundation + of + Ethical + Reasoning\%E2\%80\%9D+by+Dr.++++++++++Richard+Paul+ and+Dr.+Linda+Eler+\&gs_l=serp.3...653358.657835.1.659221. 29.11.0.1.1.7.153.812.8j1.9.0...0.0...1c.1j2.12.psy-ab.EwatmR1 ae64\&pbx=1\&bav=on.2,or.r_cp.r_qf.\&fp=6827418bb4231c9c \&biw $=1366 \& b i h=643$

18) Reflection on "What would you do?" available at http://www.youtube.com/watch?v=7R-QKDCCJM0

19) Reflection on "Homeless \& poverty" available at http://www.youtube.com/watch?v=1Rb_z7ie-uM

20) Reflection on "An analysis of the critiques of multicul- 
tural education” by Christine Sleeter (1995) (Banks \& Banks, Handbook of Research on Multicultural Education, 1995: pp. 81-94).

In the paragraph that follows, I would like to discuss the reasons as to why I have chosen the above journal entry topics and related resources. Mark Johnson (1993) conceptualized that human beings are able to move beyond narrow self-interests or place meaningful focus on the needs of the others, only when the individuals are sufficiently able to take the perspective of another with whom their own needs and interests conflict. Johnson (1993) poignantly presented such conceptualization in the following quotes:

Unless we can put ourselves in the place of another, unless we can enlarge our own perspective through an imaginative encounter with the experience of others, unless we can let our own values and ideas be called into questions from various points of view, we cannot be morally sensitive... It is not sufficient to merely manipulate a cool, detached "objective" reason toward people to inhabit their worlds (pp. 199-200).

According to the classical study by Stotland (1969) and the contemporary study by Batson, Early, \& Salvanani (1997) about human beings' perspective-taking ability, there are two different types of perspective-taking: 1) imagine-self perspective that refers to imagining what one's thoughts and feelings would be if one were in the situation of a person in need, which produces a combination of self-oriented distressed feelings and other-oriented empathetic feelings; and 2) imagine-other perspective that refers to imagining the thoughts and feelings of the person in need, which produces only empathetic feelings towards others. The imagine-self perspective is the type that stimulates character growth and moral integrity (Batson, 2008; Johnson, 1993). To actually be moral, a person should first imagine him or herself in the other's place (Batson, 2008: p. $62)$. The aforementioned journal entry topics and related resources deemed to put students in a position that stimulates the students to take the imagine-self perspective, and the ability to become involved with the imagine-self perspective is very important, or even critical, in the character growth of the students in multicultural education.

\section{Exemplary Student Journals}

\section{Example 1: Reflection on LGBT Bullying in Schools.}

I did look around the provided website, and I found it to be a great resource for LGBT information and education. It also gives a lot of useful information about statistics and laws that are currently in place that could be considered prejudice or discriminatory towards members of the LGBT community. I don't need to read an article to understand the repercussions and rate of bully of LGBT students because I live it every day. As a member of the LGBT community, there are several stereotypes, prejudices, and offensive comments that I face on a weekly if not daily basis. While I have been luckier than others with having an accepting family and friend base for support, there are a lot of insensitive remarks that are made on a daily basis by the majority of people that I have become almost numb to hearing. Not all of these, but the majority of them are more often heard coming from the mouths of heterosexual males in society today. Some of these comments were covered in the 2011 National Climate Survey that is posted on the GLSEN website. These include, but are not limited to fag, faggot, "that's gay", fairy, queen, and the ever popular "no homo."

All of these phrases are offensive to members of the LGBT community and are not socially acceptable words. Using these words or phrases in a derogatory manner such as they are, it is basically saying that being gay is a bad thing, and something that should be looked down upon or that makes you less of a person. There have been some huge strides recently for LGBT rights, but bullying of LGBT students is still a huge issue in schools today. There are some fantastic websites like the Trevor Project and the "It gets better" campaign that both work to encourage LGBT students to "hang in there" because life does get better and improve. They also offer great resources for students that are being bullied to get advice or help before they do something reckless like commit suicide or possibly harm other students. Some of the biggest issues personally to me are the prejudices that are present and placed by school corporations themselves. One of the biggest that comes to mind and matches this time of year is prom. In most public schools, homosexual couples are not allowed to attend prom together. This was also an issue for me in my senior year of high school, and I never ended up attending my own senior prom.

I truly hope one day that members of the LGBT community will see true equality in all measures of the word and their deserved constitutional rights. Prejudice and unlawful persecution are both something that should not be allowed to happen whether it be towards people because of race, gender, sexual orientation, religion, or race. This issue is something that is truly important to me because as a teacher I will now hopefully have the power to help children see diversity and help to avert attitudes that would otherwise be judgmental of those that are different. However, I also fear for my job security in the state as there is no law preventing firing someone based on his or her sexual orientation. I am also worried because in this state parents have the right to have their child moved out of my classroom if they have an issue with my sexual orientation. While I am not required to share with people publicly what my sexual orientation may be, I am always afraid that I may slip up and someone will find out the person I am and it endangers my job. While I am in no way ashamed of who I am, it is something that I constantly worry about. In my opinion, someone should not have to worry about being himself or herself for fear of losing a job, students and parents' respect, or anything else. The fact that I have to worry about this issue at all proves to me that while our country has made huge strides towards equality, the true prize of "liberty for all" is not yet close to being truly attained.

\section{Example 2: Color Blindness or Color Awareness}

In lecture, we discussed the idea that multicultural competency requires not color-blindness, as has been advocated for in the past, but rather a heightened sense of color-awareness. This initially struck me as odd, and is an issue I have wrestled with since. While I certainly understand the potential negative ramifications of extreme color-blindness, there are also clear problems with extreme color-awareness. Fortunately, it is not an either/or prospect, and recognizing the place for both colorblindness and color-awareness within the classroom will have positive ramification.

The dangers of color-blindness, as discussed in class, is that everyone is treated the same regardless of needs. While this 
seems to be a fair practice, it does not lead to equity. Some students come to the classroom with a slimmer chance at success than others based on their opportunities outside of the classroom. One of our jobs as teachers is to help minimize those disadvantages so that all students have the opportunity to succeed not only in our classroom, but as they move on. In contrast, there are also dangers of heightened color-awareness. If we focus on a student's racial status or cultural background, we may inadvertently propagate the idea that said student is disadvantaged due to some inferiority in his/her race or culture. In reality, any disadvantages a student may have are caused by the combination of a variety of factors, of which race and culture may only play a small role.

Ultimately, as a teacher, I need to be both color blind and color aware. Lesson plans need to be made in a way that are sensitive to all races, creeds, cultures, and genders. Meanwhile, the strive for equity needs to be made based on an understanding of each child's personal and family background, not just their racial or cultural identity.

\section{Example 3: Boston Marathon Bombing.}

As we all know, Muslim racism has increased since 911. I know that when I see a Muslim, the thought of terrorism runs through my mind. I am not a racist towards Muslims. I wouldn't treat them any different from anyone else. It is sad that a few people can ruin things for the entire group. Just because of a few extremists, the world is left with a fear of Muslims. This fear was proven true again last week in the Boston Marathon bombings. The two suspects were Muslims. They were not from the typical area of Iraq, Afghanistan, or Iran. They were from a small area in Russia. The majority of Russia is not Muslim. The bombers supposedly did this for political reasons. The older brother was the ring leader of this all according to the broadcasted news reports. A couple years ago, he took a trip back to his native land and became very religious. Russia even went as far as telling the United States government that he may have ties to extremists. The United States found no evidence of this. I am sure somebody is getting fired now for not catching this terrorist. This fear has caused Americans and people worldwide to become anti-Muslims. Our book says in 2004, anti-Muslim violence had increased by $50 \%$ in the past year. I can see how this could be true. Like any other sovereign nation's people, our country has many patriotic people as well. Some of these people can become an extremist if terrorists such as Boston Bombers kill peace-loving civilians like Boston marathoners. It is our predilection (natural or default state of our minds) to protect our home, family, and nation. I am sure many of these anti-terrorists crimes fly under the radar as well. I can think of one situation that angered Muslims by watching TV news. I remember a church somewhere in the US was going to burn the Quran. This set off the Muslims; this is their bible after all. Violence on this earth just needs to stop. Whether this violence comes from Muslims or anti-Muslim hate crimes, it is not right. The world we live in is a scary place and it needs to become peaceful once again.

Those above three examples are selected because of three reasons. First, those three examples are agreeable with the overall spirit of multicultural journal writings. The three examples demonstrate the ability to take the perspective of imagineself with a multicultural sensitivity heightened to the level that allows the students to be fluid enough to exude to and from all facets of LGBT issues, the limitations of having only binary views, and the concurrent issue of Boston marathon bombing. Second, those three examples adequately satisfy the requirement of authenticity, creativity, and reflectivity in that each entry speaks in terms of the first person, yet balanced enough to be able to see the multicultural issues from the others' viewpoints as well. Third, the three examples are either sufficiently transformative or characterization-oriented. I admire the courage that Example 1 makes evident, and whole-heartedly agree with the statement that, "someone should not have to worry about being himself or herself for fear of losing a job, students and parents' respect, or anything else.” The entry maintains a professional composure and performs to the rubric standards, or even beyond, with authenticity, heightened interpersonal (or cross-cultural) sensitivity, and characterization of multicultural values. I chose the Example 2 entry because I have had to learn from the journal writing. The course textbook conveys that the traditional color-blind approach of interacting with the contemporary diverse American student population is now dysfunctional and obsolete, and so I lectured and led class discussions within such framework. However, I learned that the author of Example 2 is a more independent thinker than the instructor, who is able to resist the mental trap of the binary thinking of either-or alternatives or zero-sum games. I liked the Example 3 entry for its fluidity with which the author maintains utmost patriotism towards the American causes (i.e., American people are willing to protect their own family, home, and nation by default or predilection), yet is able to grasp the social occurrences from the others' perspective (i.e., the Muslim perspective of watching some American Christians burn the Quran, the bible of the Muslim religion). In addition, I liked the conclusion of the Example 3 that calls for an unconditional cessation of hateful crimes from both sides, not to retaliate from the victims' side and no more terrorist attacks from a few extremists.

\section{Conclusion}

By default of writing extensive journals, students should engage themselves in deep reflections about multicultural issues, in writing about topics of personal interest and choice, in expressing their perspective, in arguing and counter-arguing about the issues of interest, and eventually being able to connect new information with things that they already knew. Moreover, students are encouraged to actively engage in their own learning process because the journal writing activities provide students with opportunities to clarify and analyze their ideas, values, perspectives, experiences, and thinking. When appropriately guided with adequate journal topics and cognizant resources, students should be able to compare and contrast, to evaluate, and to synthesize newly-learned ideas with their existing value system. Ultimately, if students create one's own action plans in their journal writings, pertaining to the rectification of their existing predilections, stereotypes, and prejudices, those journal writings become the evidence of characterizations, the highest affective development in which one's behaviors and value system are consistent. With those conceptualizations of constructivists' approach, the journal writing assignment has been the most weighted learning activity of the students in my multicultural education course. Constructing a rubric for journal quality evaluation and exploring those suggested topics of journal entries and related resources have been authentic learning experiences to many students as well as to me. Where the 
term authenticity refers to the experiences or statements that are supported by unquestionable first-hand evidence, I am truly convinced by the authentic efficacy of journal writings in the character growth of students in multicultural education. Over the journey of my learning and teaching practices, there have been a few occasions where I have had to wipe off tearstains from my reading glasses, and all of these occasions occurred while reading students' journals. I admit that these dramatic experiences have been rare; however, I am always able to delve into deep dialogues with my students when I read their journals. Where journal writing is conceptualized as refined dialogues between learners and teachers, it has been a most reliable teaching strategy in my multicultural education course.

\section{REFERENCES}

Banks, J. A. (2009). Teaching strategies for ethnic studies (8th ed.). Boston, MA: Pearson Allyn \& Bacon.

Banks, J. A. (2014). An introduction to multicultural education (Vol. 5th). Upper Saddle River, NJ: Pearson.

Banks, J. A., \& Banks, C. A. (1995). Handbook of research on multicultural education. New York: Macmillan.

Batson, C. D. (2008). Moral masquerades: Experimental exploration of the nature of moral motivation. Phenomenology \& Cognitive Science, 7, 51-66. doi:10.1007/s11097-007-9058-y

Batson, C. D., Early, S., \& Salvanani, G. (1997). Perspective taking: Imagining how another feels versus imagining how you would feel. Personality and Social Psychology Bulletin, 23, 751-758. doi:10.1177/0146167297237008

Bennett, C. I. (2011). Comprehensive multicultural education: Theory and practice. Boston, MA: Allyn \& Bacon.

Bloom, B. (1956). Taxonomy of educational objectives, handbook I: The cognitive domain. New York: David McKay.

Check, J., \& Schutt, R. K. (2012). Research methods in education. Thousand Oaks, CA: Sage.

Cook, I. (2000). "Nothing can ever be the case of 'us' and 'them' again": Exploring the politics of difference through border pedagogy and student journal writing. Journal of Geography in Higher Education, 24, 13-27. doi:10.1080/03098260085108

Cook, P. J., \& Ludwig, J. (2008). The burden of “acting white”: Do black adolescents disapage academic achievement? In J. U. Ogbu (Ed.), Minority status, oppositional culture, \& schooling (pp. 275297). New York: Routledge.

Dompnier, B., Darnon, C., \& Butera, F. (2009). Faking the desire to learn: A clarification of the link between mastery goals and academic achievement. Psychological Science, 20, 939-943. doi:10.1111/j.1467-9280.2009.02384.x

Elik, N., Wiener, J., \& Corkum, P. (2010). Pre-service teachers’ open- minded thinking dispositions, readiness to learn, and attitudes about learning and behavioural difficulties in students. European Journal of Teacher Education, 33, 127-146. doi:10.1080/02619760903524658

Ford, D. Y. (2011). Multicultural gifted education (2nd ed.). Waco, TX: Prufrock Press Inc.

Fraenken, J. R., \& Wallen, N. E. (2009). How to design and evaluate research in education. New York: McGrow-Hill.

Giroux, P. (1991). Democracy \& the discourse of cultural difference: Toward a politics of border pedagogy. British Journal of Sociology of Education, 12, 501-519. doi:10.1080/0142569910120406

Johnson, M. (1993). Moral imagination: Implications of cognitive science for ethics. Chicago: University of Chigago Press.

Kerger, S., Martin, R., \& Brunner, M. (2011). How can we enhance girls' interest in scientific topics? British Journal of Educational Psychology, 81, 606-628. doi:10.1111/j.2044-8279.2011.02019.x

Krathwohl, D. R., Bloom, B. S., \& Masia, B. B. (1964). Taxonomy of educational objectives: Handbook II. Affective domain. White Plains: Longman Inc.

McMillan, J. H. (2007). Classroom assessment: Principles and practice for effective instruction (4th ed.). Boston: Allyn and Bacon.

Nolen, A., \& Vander Putten, J. (2007). Action research in education: Gaps in ethical principles and practices. Educational Researcher, 36, 401-407. doi:10.3102/0013189X07309629

Popham, W. J. (2011). Classroom assessment: What teachers need to know. Boston, MA: Allyn \& Bacon.

Poulou, M. S. (2009). Classroom interactions: Teachers' and students' perceptions. Research in Education, 82, 103-106. doi:10.7227/RIE.82.9

Reeve, J. (2005). Understanding motivation and emotion (4th ed.). New York: John Wiley \& Sons Inc.

Sarwar, M., Yousuf, M. I., \& Ranjha, A. N. (2011). Usefulness and level of interest in Pakistan national curriculum subjects: Secondary school students' perceptions. International Journal of Academic Research, 3, 964-969.

Shadreck, M., \& Isaac, M. (2012). Science teacher quality and effectiveness: Gweru Urban Junior Secondary School students' points of view. Asian Social Science, 8, 160-165. doi:10.5539/ass.v8n8p160

Shirbagi, N. (2010). An exploration of undergraduate students' motivetion and attitudes towards English language acquisition. Journal of Behavioural Sciences, 20, 1-14.

Sleeter, C. E. (1995). An analysis of the critiques of multicultural education. In J. A. Banks, \& C. A. Banks (Eds.), Handbook of research on multicultural education (pp. 81-94). New York: Macmillan.

Stotland, E. (n.d.). Exploratory investigations of emphathy. In L. Berkowitz (Ed.), Advances in experimental social psychology (Vol. 4, pp. 271-313). New York: Academic Press.

Williams, R. B., \& Dunn, S. E. (2008). Brain compatible learning for the block (2nd ed.). Thousand Oaks, CA: Corwin Press. 